\title{
Patient safety culture in the maternal-child area of a university hospital
}

\author{
Cultura de segurança do paciente na área materno-infantil de hospital universitário \\ Cultura de seguridad del paciente en el área materno-infantil de un hospital universitario
}

\section{Vitoria Sandri Pedronia \\ Helga Geremia Gouveiaa Letícia Becker Vieira ${ }^{a}$ \\ Wiliam Wegnera \\ Adriana Catarina de Souza Oliveirab Maxuel Cruz dos Santos ${ }^{a}$ Franciela Delazeri Carlotto ${ }^{a}$}

How to cite this article: Pedroni VS, Gouveia HG, Vieira LB, Wegner W, Oliveira ACS, Santos MC, Carlotto FD. Patient safety culture in the maternal-child area of a university hospital. Rev Gaúcha Enferm. 2020;41(esp)::20190171. doi: https://doi.org/10.1590/19831447.2020.20190171

\footnotetext{
- Universidade Federal do Rio Grande do Sul (UFRGS), Escola de Enfermagem. Porto Alegre, Rio Grande do Sul, Brasil.

- Universidade de Múrcia. Múrcia, Espanha.
}

\section{ABSTRACT}

Objective: To describe the safety culture of the patient from the perspective of nurses and physicians working in the maternal-child area.

Method: A cross-sectional study conducted from January to September 2018 with 41 professionals of the Obstetrics Center and obstetric hospitalization of a university hospital in the south of the country. The Hospital Survey on Patient Safety Culture was used, with 12 dimensions of the safety culture, measured by means of a general score $(0$ to 10$)$ and of positive answer percentages to assess strengths and weaknesses.

Results: The action of supervisors/bosses can be considered a strength of patient safety, with $78.2 \%$ of positive answers; already regarding communication, it was considered a fragility, punctuating $13.24 \%$. The general safety grade of the patient assigned to the work's unit was very good, in a confidence interval of $95 \%$.

Conclusion: With the identification of the strengths and weaknesses of patient safety, it is possible to plan improvement actions. We emphasize that the non-punitive approach is essential.

Keywords: Patient safety. Organizational culture. Quality of health care. Maternal and child health.

\section{RESUMO}

Objetivo: Avaliar a cultura de segurança do paciente na perspectiva de enfermeiros e médicos atuantes na área materno-infantil.

Método: Estudo transversal, realizado de janeiro a setembro de 2018, com 41 profissionais do Centro Obstétrico e internação obstétrica de hospital universitário do sul do país, utilizando o Hospital Survey on Patient Safety Culture, com 12 dimensões da cultura de segurança, mensuradas por meio de um escore geral $(0$ a 10$)$ e percentuais de respostas positivas para aferir fortalezas e fragilidades.

Resultados: A ação de supervisores/chefes foi considerada uma fortaleza, tendo 78,2\% de respostas positivas; já no que diz respeito à comunicação, considerou-se uma fragilidade, pontuando 13,2\%. A nota geral de segurança do paciente foi de muito boa, nota 4, num intervalo de confiança de $95 \%$.

Conclusão: Com a identificação das fortalezas e fragilidades da segurança do paciente é possível planejar ações de melhoria. Destacamos que a abordagem não punitiva é essencial.

Palavras-chave: Segurança do paciente. Cultura organizacional. Qualidade da assistência à saúde. Saúde materno-infantil.

\section{RESUMEN}

Objetivo: Describir la cultura de seguridad del paciente en la perspectiva de enfermeros y médicos actuantes en el área maternoinfantil.

Método: Estudio transversal realizado de enero a septiembre de 2018 con 41 profesionales del Centro de Obstetricia y del área de internación obstétrica de un hospital universitario del sur del país. Se utilizó la Hospital Survey on Patient Safety Culture (Encuesta hospitalaria sobre la cultura de la seguridad), con 12 dimensiones de la cultura de seguridad, medidas por medio de un puntaje general ( 0 a 10$)$ y de porcentajes de respuestas positivas para evaluar fortalezas y debilidades.

Resultados: La acción de supervisores/jefes puede ser considerada una fortaleza de la seguridad del paciente, con el 78,2\% de respuestas positivas; en lo referente a la comunicación, se la consideró una debilidad, con el 13,24\%. La nota general de seguridad del paciente asignada a la unidad de trabajo fue muy buena, en un intervalo de confianza del 95\%.

Conclusión: Al identificar las fortalezas y debilidades en la seguridad del paciente es posible planificar acciones de mejora. Destacamos que el enfoque no punitivo es esencial.

Palabras clave: Seguridad del paciente. Cultura organizacional. Calidad de la atención de salud. Salud materno-infantil. 


\section{口INTRODUCTION}

Maternity needs to be understood as a different organization within the institution, due to the fact that it takes care of two people at the same time, and that they do not necessarily have a clinical condition of disease since pregnancy, childbirth and the puerperium are physiological processes ${ }^{(1)}$.

Approximately three million births occur in Brazil each year, with six million patients (women and newborns) needing assistance. Due to the large number of patients, the potential for adverse events to occur during the care process is strong, and patient safety must also reach the maternal and child context, as within this care area there is still a very serious adverse event: maternal mortality ${ }^{(1)}$. Inadequate care provided during labor is a factor strongly associated with maternal mortality since simple interventions could prevent this mortality rate ${ }^{(2)}$. The decrease in the Brazilian maternal mortality rates is a challenge both for the health institutions and for society. The high rates found (in 2010, the maternal mortality ratio was 68 per 100,000 live births) constitute a violation of the human rights of women and children and is considered a public health issue $\mathrm{e}^{(3)}$.

The safety culture assessment is determined by international hospital accreditation bodies and provides for the identification and management of the safety issues in the institutional work process in order to monitor changes and outcomes $^{(4)}$. According to the 2013 National Patient Safety Policy the concept of patient safety culture refers to the culture in which all workers, including those involved in care and management, take responsibility for their own safety, for the safety of their colleagues, patients and family members; prioritizing safety over financial and operational goals; encouraging and rewarding those who identify, notify and resolve security issues. Maternity needs to be understood as a different organization within the institution, because it takes care of two people at the same time, and that, not necessarily, present a clinical condition of disease since pregnancy, childbirth and postpartum are physiological processes ${ }^{(5)}$.

In health care organizations, the patient safety culture is assessed using questionnaires. Among the most used is the Hospital Survey on Patient Safety Culture (HSOPSC), which measures the multiple dimensions of the patient safety culture. The tool interrogates the opinion of its population on key safety issues: values, beliefs and norms of the organization, adverse event reporting, communication, leadership and management ${ }^{(4)}$. The health institution where this study was conducted is constantly evolving on the issues involving security promotion and prevention of adverse events. It is believed that the findings of this study will provide moments of reflection in the professionals and discussions about the referential of patient safety in obstetrics. The relevance of the study is to impact on patient safety, maternal and child health indicators and on the quality of life of women and babies through the diagnosis of safety culture and the repercussions on patient safety actions involving the assistance. The research question was the following: how is the patient safety culture evaluated from the perspective of nurses and doctors working in the maternal-child area of a large university hospital? The purpose of the study was to evaluate the patient safety culture from the perspective of nurses and doctors working in the maternal-child area.

\section{METHOD}

This is a quantitative, descriptive cross-sectional study conducted in the maternal-child area of a university hospital in the south of the country. The health institution where this study was conducted is constantly evolving on issues involving security promotion and prevention of adverse events. It is believed that the findings of this study will provide moments of reflection in the professionals and discussions about the referential of patient safety in obstetrics.

The sample consisted of nurses, obstetricians and neonatologists from the Obstetric Center Unit (OCU) and Obstetric Inpatient Unit (OIU) of a university hospital in the south of the country by convenience sampling. The Nursing team consists of 30 obstetric nurses and the Medical team is made up of 21 obstetricians and 22 neonatologists, totaling a sample of 73 professionals. Hired professionals with more than six months of service experience were included in the sample, and those on vacation or sick leave during the data collection period were excluded. Twenty-one hired doctors, including obstetricians and neonatologists, and 20 nurses from the Obstetric Center and Obstetric Inpatient Units participated in the research, totaling 41 professionals. This is because eight professionals did not meet the inclusion criteria, eight refused to participate, three were not found during the collection period and 13 agreed to participate in the research, but did not return the data collection instrument, thus considering them as losses.

Data collection occurred from January to September 2018. The HSOPSC was initially applied to the participant's work unit and later, aiming at greater adherence of the professionals, the instrument remained with the participant to fill in, and the researcher returned it in the combined shift.

This instrument enables the assessment of the patient safety culture from the point of view of the professionals by means of 12 dimensions, with 50 items in total; 44 are related 
to specific security culture issues and six items are associated with personal information. Each of the 12 dimensions has three to four items. There are three dimensions correlated to the hospital, seven related to the unit/work sector within the hospital, and two outcome dimensions ${ }^{(6)}$.

The 12 dimensions covered in the HSOPSC are the following $^{(5)}$ :

Dimension 1 - Supervisors/Managers' safety promotion expectations and actions: assesses if the supervisors and managers consider the staff suggestions for improving patient safety, recognizes staff participation for patient safety improvement procedures;

Dimension 2 - Organizational Learning and Continuous Improvement: assesses the existence of learning from the mistakes that lead to positive change and assesses the effectiveness of the changes that have occurred;

Dimension 3 - Teamwork within Units: defines whether employees support each other, treat each other with respect, and work together as a team;

Dimension 4 - Open Communication: evaluates whether the hospital staff talks freely about the errors that may affect the patient and whether they feel free to question the staff with greater authority;

Dimension 5 - Return of the information and communication about error: evaluates the perception of the hospital staff if they notify the errors that occur, implement changes and discuss strategies to avoid errors in the future;

Dimension 6 - Non-punitive responses to errors: evaluates how the staff feels about their mistakes, whether they think their errors can be used against them and kept on their functional records;

Dimension 7 - Staffing: assesses whether the staff can handle their workload and whether the work hours are adequate to provide the best patient care;

Dimension 8 - Hospital management support for patient safety: assesses whether the hospital administration and management provide a working climate that promotes patient safety and demonstrates that patient safety is a priority;

Dimension 9 - Teamwork among the units: assesses whether the hospital units cooperate and coordinate with each other to provide a high quality care for patients;

Dimension 10 - Shift changes and internal transfers: assesses whether important patient care information is transferred through the hospital units and during shift changes;
Dimension 11 - General perception of patient safety: evaluates the existing systems and procedures in the health organization to prevent errors and the absence of patient safety problems in the hospitals;

Dimension 12 - Frequency of notified events: this relates to reporting possible patient safety issues and identified events or perceived and corrected errors before they affect the patient.

In addition, it provides professionals with a rating for patient safety and the number of event records. Each item provides five answer options through the Likert scale.

The descriptive analysis of the variables was performed using SPSS version 20. For the safety culture analysis, the percentages of positive answers to the dimensions of the patient safety culture were calculated, defined as the mean percentage of positive answers to the component items of the HSOPSC dimension. The percentage of positive answers for each dimension and the percentage of positive answers for each dimension item were calculated using specific formulas.

To calculate the percentage of positive answers for each dimension, the following formula was used:

$\% X$ dimension positive answers $=[$ Number of positive answers to the items of $X$ dimension/total number of valid answers to the items of $X$ dimension (positive, neutral, negative excluding missing data)]* ${ }^{*} 100$

And to calculate the percentages of positive answers for each dimension item, the following formula was used:

$\%$ of positive answers to dimension $X$ item $=$ [number of positive answers to dimension $\mathrm{X}$ item/total number of valid answers to dimension $\mathbf{X}$ item (positive, neutral, negative excluding missing data)] ${ }^{*} 100$

The percentage of affirmative answers represents a positive reaction to the patient safety culture and makes it possible to list strong and weak areas in the patient safety-related processes. "Strong areas of patient safety" in the hospital will be those whose positively written topics get $75 \%$ or more of positive answers or those whose negatively written items get $75 \%$ or more of the negative answers. Similarly, as "weak patient safety areas" that need improvement were considered those whose items had $50 \%$ or less positive answers ${ }^{(6)}$.

Research approved by the Research Ethics Committee of the Hospital de Clinicas de Porto Alegre under opinion number 2,230,927 and CAEE 72541317.5.0000.5327. The health professionals signed the Free and Informed Consent Form containing all the necessary information about the research. 


\section{RESULTS}

Regarding the characterization of the participants, the mean age was 42.3 years old, with a minimum age of 29 and a maximum of 67. Most of the professionals were female (92.7\%). Regarding the level of education, $2.4 \%$ only have higher education, $53.7 \%$ have a specialization and 43.6\% masters/doctorate degrees.

In their function within the hospital, $97.6 \%$ of the participants reported having direct contact with the patients. The mean time working in the current specialty/profession is 16.8 years, with a minimum of three years and a maximum of 38 , with $33.9 \%$ working 21 years or more. Considering the working time in the institution and the working time in the unit, 39\% and $36.6 \%$ of the participants, respectively, have worked between one and five years, with most professionals (87.8\%) working 20 to 39 hours. Just over half of the sample consisted of nurses and most of the participants work in Obstetrics (Table 1).

Next, the findings related to the themes which refer to the dimensions evaluated using the HSOPSC instrument will be described. Following the guidelines of the authors of the instrument, the questions pertaining to each dimension obtained a percentage of positive, negative and neutral answers (Figure 1).
The results showed that four of the 12 dimensions can be classified as patient safety strengths, as they obtained a percentage of positive answers above $75 \%$, as follows: D1, D2, D3, and D8 that address, respectively, supervisory/ managerial security promotion expectations and actions; organizational learning and continuous improvement; teamwork within units and support of hospital management for patient safety. This finding is contrary to a study conducted in neonatal intensive care units in the city of Florianópolis, where none of the 12 dimensions obtained a percentage above $75 \%$ to be classified as a patient safety strengths $s^{(5)}$.

Regarding the number of reports of adverse events in 12 months, 14 professionals (34.1\%) completed three to five notifications, nine professionals (22\%) reported having completed one or two notifications and one participant (2.4\%) considered having completed 21 or more adverse event notifications. It is noteworthy that 17 professionals (41.5\%) did not notify any event.

Regarding the assessment of patient safety in their hospital work unit, a considerable portion of participants (78\%) considered it very good, with the mean grade given to the unit being 4. Two participants did not answer this section of the questionnaire (Table 2).

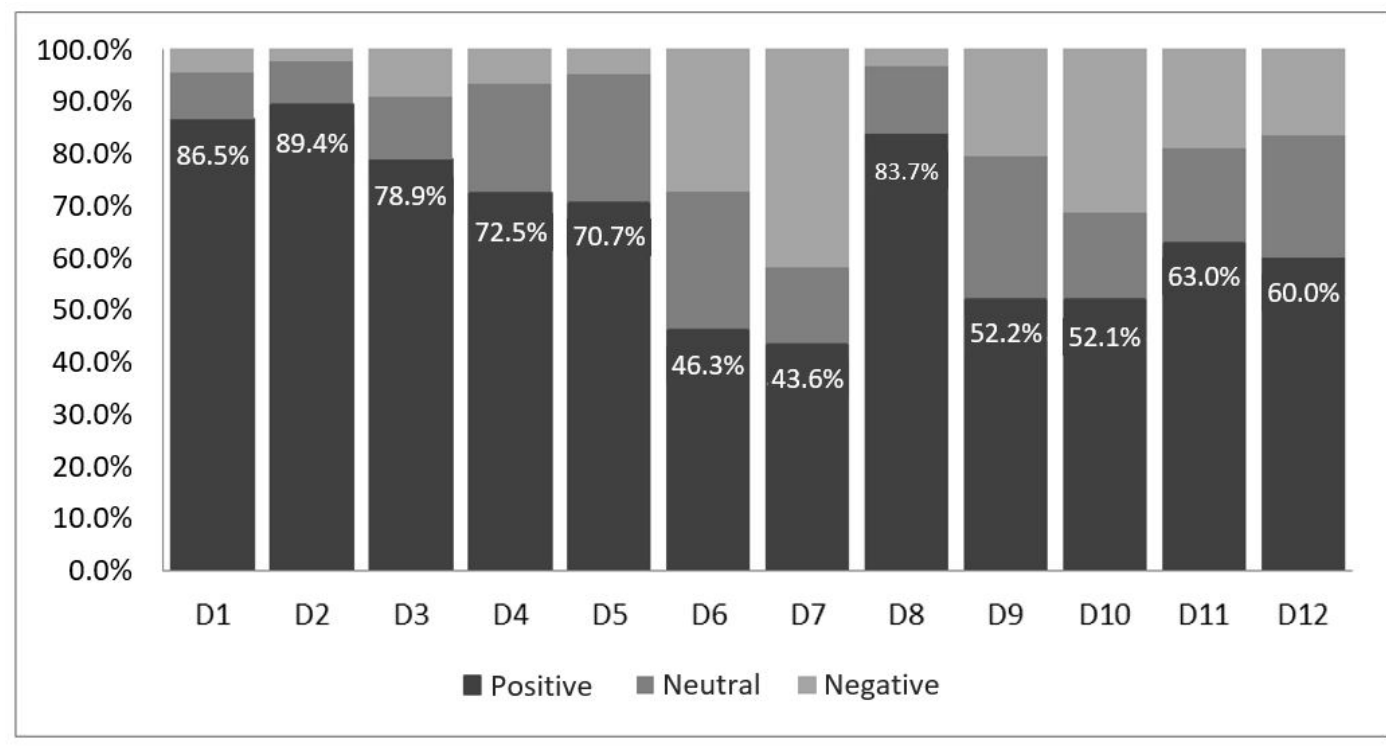

Figure 1 - Percentage of positive answers from the 12 dimensions of the patient safety culture according to the HSOPSC in the maternal-child area of a university hospital in the south of Brazil, 2018

Source: Research data, 2018

Where D1 = Dimension 1, D2 = Dimension 2 and so on 
Table 1 - Characterization of the sample of participating professionals, Rio Grande do Sul, Brazil, 2018. Porto Alegre, RS, Brazil, 2018. $(n=41)$

\section{Variable $n(\%)$}

Contact with the patient

\begin{tabular}{cc}
\hline Yes & $40(97.6)$ \\
\hline No & $01(2.4)$
\end{tabular}

\section{Time worked in the current specialty/profession}

\begin{tabular}{lc}
\hline 1 to 5 years & $03(7.2)$ \\
\hline 6 to 10 years & $07(19.4)$ \\
\hline 11 to 15 years & $11(26.9)$ \\
\hline 16 to 20 years & $04(9.6)$ \\
\hline 21 years or more & $14(33.9)$ \\
\hline Not informed & $02(4.9)$
\end{tabular}

Working time at this hospital

\begin{tabular}{lc}
\hline Less than a year & $01(2.4)$ \\
\hline 1 to 5 years & $16(39)$ \\
\hline 6 to 10 years & $09(22)$ \\
\hline 11 to 15 years & $03(7.3)$ \\
\hline 16 to 20 years & $04(9.8)$ \\
\hline 21 years or more & $08(19.5)$ \\
\hline Working time in the current area/unit & $02(4.9)$ \\
\hline Less than a year & $15(36.6)$ \\
\hline 1 to 5 years & $09(22)$ \\
\hline 6 to 10 years & $03(7.3)$ \\
\hline 11 to 15 years & $04(9.8)$ \\
\hline 16 to 20 years & $08(19.5)$ \\
\hline 21 years or more & \\
\hline Weekly workload & $36(87.8)$ \\
\hline Between 20 and 39 hours & $02(4.9)$ \\
\hline Between 40 and 59 hours & $02(4.9)$ \\
\hline Between 80 and 99 hours & $01(2.4)$ \\
\hline 100 hours or more & $21(51.2)$ \\
\hline Profession & $20(48.8)$ \\
\hline Medical assistant & $02(4.9)$ \\
\hline Nurse & $09(22)$ \\
\hline Service & $29(70.7)$ \\
\hline Pediatrics & \\
\hline
\end{tabular}

Source: Research data, 2018. 
The percentage of positive answers found in the analysis of the instrument indicates strong areas of patient safety (called strengths), and fragile areas of patient safety (called weaknesses), presented in Table 3.

Regarding the actions and expectations of supervisors/ bosses, assessing whether they consider the suggestions of the workers to qualify patient safety and recognize the participation of the work team for quality and patient safety procedures, it was possible that it is considered a strength of patient safety, with $98.6 \%$ of positive answers.

As for communication, it assesses whether the hospital workers talk freely about the safety incidents that may affect the patient, whether they feel free to ask their boss$\mathrm{es}$, and whether the employees receive information about the incidents that happen in their unit/are, if changes are implemented and if they discuss strategies to avoid future incidents. This theme obtained $29.9 \%$, indicating a weakness of patient safety in the maternal-child area of the hospital in the communication dimension.
Considering the weaknesses of patient safety, a positive answer percentage of $42.3 \%$ was found in situations concerning the institution in which the professional works, addressing items such as: hospital management support for patient safety, the working environment provided, if patient safety is a priority for the management; it also questions teamwork among the hospital units; and addresses the time of shift change, questioning whether important patient information is not lost during shift changes or patient transfers.

On the other hand, specifically the theme of the work unit of the interviewed professional, items being evaluated such as teamwork within the unit, questioning if the professionals support each other and treat each other with respect; also questioned whether the professionals are able to handle their workload without compromising patient care and about how often errors that would not cause harm to the patient or were perceived before causing harm are reported, and how often the notification of

Table 2 - Patient safety assessment, percentage of positive answers and Mean overall score for patient safety, Brazil, 2018

\section{Variables}

n (\%)

$$
\text { Grade }
$$

\begin{tabular}{lc}
\hline Grade 5 - excellent & $03(7.3)$ \\
\hline Grade 4 - very good & $32(78)$ \\
\hline Grade 3 - regular & $04(9.8)$ \\
\hline Mean $(95 \%$ Cl) & $4.2(3.9-4.32)$ \\
\hline PPA & $35(89.74)$ \\
\hline
\end{tabular}

Source: Research data, 2018.

PPA = Percentage of Positive Answers. Does not totalize $100 \%$ due to the possibility of

neutral, negative and missing answers.

Grade $=$ Mean value of the overall grades given to patient safety.

Table 3 - Percentage of positive answers according to the dimensions of the questionnaire. Brazil, 2018

\section{Topics covered $\quad \%(95 \% \mathrm{CI})$}

\begin{tabular}{lc} 
Your unit of work/teamwork & $57.7(50.02-65.39)$ \\
\hline Actions and expectations of supervisors/bosses* & $98.6(92.45-104.84)$ \\
\hline Communication** $^{*}$ & $29.9(23.58-36.23)$ \\
\hline Frequency of reported events & $74.7(55.57-94.02)$ \\
\hline In your institution/problems in the shift changes and transfers** & $42.3(37.11-47.58)$
\end{tabular}

Source: Research data, 2018

* Dimensions classified as strengths;

** Dimensions classified as weaknesses. 
errors that could cause harm to the patient could not be considered as a weakness or strength, with a percentage of $57.7 \%$ and $74.7 \%$ respectively.

\section{口ISCUSSION}

The strategies for promoting patient safety are actions that can be provided by the various professional categories. In this study, doctors and nurses were interviewed, who represent the main professionals responsible for assisting the mother-baby binomial. Comparing data from professionals participating in this survey with others from a survey conducted in the northeast of the country ${ }^{(7)}$ we can observe that the findings are equivalent when it comes to the weekly workload worked and the time worked in the current unit within the institution. Although the professionals in the present study indicated working 21 years or more in their current profession, the working time in the current institution is equivalent to that found in the study ${ }^{(8)}$.

Regarding the frequency of the reported events, the findings of this study were not enough to classify it as a strength or as a weakness. This data is in line with the results found in a study conducted in the hemodialysis sector of a hospital where 517 reports of adverse events witnessed or reported by the professionals were informed ${ }^{(9)}$. In another study, within a period of four years, 42 adverse event reports were obtained, showing the low prevalence of notifications ${ }^{(10)}$. Low adverse event reporting rates lead the authors to think of underreporting of adverse events. Thus, it is important to promote meetings and/or training so that the team is informed about the importance of notifications since, in this way, strategies for improvement in care can be thought, apart from stressing that notifications are not punitive.

The professional's difficulty regarding the concept of adverse event may be associated with the low notification rates. Results from a survey show that $82.76 \%$ of the health professionals admit that there are differences between a medication incident and an adverse event, but 31\% cannot differentiate this concept ${ }^{(11)}$. Another factor strongly related to the low rate of adverse event notifications is the work overload and the low staff size ${ }^{(7)}$. Corroborating with these findings, a study ${ }^{(7)}$ conducted with the same instrument used in this research considered the reduced number of professionals as a factor for the underreporting of adverse events which, together with the work overload, generated a rate of $95.9 \%$ of answers indicating a number of adverse events between one and five ${ }^{(12)}$ in the last 12 months.

In one of the dimensions of the HSOPSC, which addresses the amount of staff enough to handle the workload in the work unit, a significant number of professionals in the present study disagreed. Work overload can be justified by the inadequate number of professionals in the institution and it is possible to relate patient safety with the correct staffing, since the mortality rate has been higher in hospitals with inadequate staffing ${ }^{(13)}$.

In the present study, a portion of the professionals reported that the error can be used against the professional himself, a finding that corroborates with a study conducted in Intensive Care Units of a teaching hospital in São Paulo, which pointed out the non-punitive answer to errors as being the largest weakness of the patient safety culture ${ }^{(14)}$.

Discussions about errors are still recent in Brazil, but the culture that the error falls on the person and not on the problem is strongly rooted from the training of the professionals $s^{(14)}$, which fosters low adverse event reporting rates.

For incident reporting to be effective and to enable changes in the institution, a great deal of effort is required from managers to assure the professionals that the objective is to improve patient safety and not to punish the employee ${ }^{(15)}$. The occurrence of errors should be interpreted as failures resulting from collapses of the organizational assistance system and not as an isolated result of the actions of a professional(16).

Regarding the expectation of supervisors/bosses, a study conducted in Santa Catarina, points out that professionals are not comfortable answering questions that address the conduct of their supervisor or hospital administration, and $50 \%$ of the interviewed professionals remained neutral in relation to their expectations in their answers ${ }^{(5)}$. Although some professionals are still not comfortable answering questions about leadership, this theme was one of the strengths of patient safety in the institution studied, which indicates certain satisfaction of the professionals regarding the conduct of supervisors/bosses, a fact that may stimulate the health team in the involvement and qualification of care and, consequently, in patient safety. Building on this strength of patient safety, managers should choose a participatory horizontal management model(12) aiming to further strengthen the relationship with the staff and to strengthen the patient safety culture.

In contrast to the results of this research, a study conducted in three Pediatric Emergency Units of Greater Florianópolis pointed out the difficulty of the professionals in recognizing the concern of the managers regarding patient safety issues and reaffirms the existence of a culture of guilt and punishment, indicating the need for changes in the current culture of these units(7).

Regarding the patient safety score in the institution studied, we found that, in general, patient safety was considered very good. This grade is higher than that found in a study 
conducted in different countries that evaluated the patient safety culture using the original version of the questionnaire, where less than $50 \%$ of the participants considered patient safety to be very good(6).

Although the themes analyzed classified as patient safety strengths are still few, this data is in line with a research conducted in Neonatal Intensive Care Units of a São Paulo teaching hospital, where the areas of patient safety strengths are not evident while the areas of weaknesses indeed are; most of the professionals highlighted patient safety as fair and very good ${ }^{(7)}$. A Dutch research, developed in 26 emergency units with the participation of 730 professionals, corroborates this finding in which patient safety was mostly assessed as fair and very good ${ }^{(17)}$.

In contrast, a research conducted in two hospitals in Paraná, one public and one private, shows that workers' assessment of patient safety in institutions is not positive, emphasizing that problems in patient safety have important financial, social and psychological repercussions, such as cost increases and temporary or permanent interruption of the work process, which affect both the patient and the institution ${ }^{(12)}$.

We can observe that there is a discrepancy regarding the assessment of patient safety by the health professionals in different countries, institutions and care context. This fact may be associated with the level of implementation of the patient safety culture, considering that it can stimulate reflection and critical sense in the professionals. In countries where the safety culture is already better structured and present, evaluations are more thorough ${ }^{(7)}$.

As for the theme that addresses communication, it was considered a weakness. This finding is in line with another study that compared the patient safety culture in different countries (Japan, Taiwan and the United States of America). In Taiwan, a low percentage of positive communication-related answers was identified, which is justified by the fact that the Chinese culture is characterized by an authoritarian leadership, which inhibits the manifestation of professional concerns and patient safety issues ${ }^{(18)}$.

Another factor that contributes to communication scoring as a weakness is the shift change or unit transfer. A study evaluating the culture and organizational climate for patient safety in an Intensive Care Unit states that important information to promote patient safety may be lost at this time of communication among teams ${ }^{(14)}$.

Teamwork among units, shift change, unit transfer and communication are priority areas for actions to improve the patient safety culture ${ }^{(8)}$. The shift change is considered a patient safety strategy for nurses and it is through this that the nursing team integrates with the patients' routine; at this moment, it is possible to visualize the inpatient's condition and all his particularities, so that strategies can be prepared that can prevent possible failures ${ }^{(19)}$. The same can be considered in relation to the health professionals in other areas, since the shift change will provide subsidies for the continuity of care. Thus, it is recommended using a tool that allows for the recording of the information of the day worked, guaranteeing the continuity of the assistance ${ }^{(20)}$.

\section{口CONCLUSION}

Although most of the professionals rate patient safety as very good in their work unit, it can be observed that only one theme was classified as a strength, which refers to the actions and expectations of supervisors/bosses. The main weaknesses found were related to communication and problems with shift changes and transfers. The themes involving the unit of work/teamwork and the frequency of reported events were not characterized as either strengths or weaknesses by the frequency presented. With the identification of the weaknesses and for the themes where neither a weakness nor a strength was identified, it is possible to think of improvement measures and strategies that can be implemented in the units studied, according to their assistance model, which may help in reducing maternal mortality. By identifying the strengths and weaknesses of patient safety it is possible to plan improvement actions. We emphasize that the non-punitive approach is essential.

We emphasize the importance of the non-punitive approach, as it is essential to record the reports of the adverse events notified, because only in this way it is possible to have a real overview of what happens in the institution that enables the development of action plans that will guide the qualification of care.

As a limitation of the study we can consider the low adherence of the medical team that, even after the initiative of the instrument to remain with the professional for later return, did not accept to participate in the study or did not return the collection material, being considered as refusal.

Identifying the institution's safety culture and the professionals' perception on this same theme allows for the implementation of improvements for areas identified as weaknesses and motivates the continuity of strongly established actions, allowing for a harmless and better quality assistance. Based on the result found that communication is classified as a weakness in patient safety, it is emphasized that nursing has the role of qualifying its records as they guide the care process. 


\section{REFERENCES}

1. Agência Nacional de Vigilância Sanitária (BR). Serviços de atenção materna e neonatal: segurança e qualidade. Brasília, DF: Anvisa; 2014 [cited 2019 Apr 10]. Available from: https://www20.anvisa.gov.br/segurancadopaciente/index. php/publicacoes/item/servicos-de-atencao-materna-e-neonatal-segurancae-qualidade

2. Guerra AB, Guerra LM, Probst LF, Gondinho BVC, Ambrosano GMB, Melo EA, et al. Can the primary health care model affect the determinants of neonatal, post-neonatal and maternal mortality? a study from Brazil. BMC Health Serv Res. 2019;19(1):133. https://doi.org/10.1186/s12913-019-3953-0

3. Áfio ACE, Araújo MAL, Rocha AFB, Andrade RFV, Melo SP. Maternal deaths: the need to rethink coping strategies. Rev Rene. 2014;15(4):631-8. doi: https://doi. org/10.15253/2175-6783.2014000400010

4. Reis (T, Laguardia J, Martins M. Adaptação transcultural da versão brasileira do Hospital Survey on Patient Safety Culture: etapa inicial. Cad Saúde Pública. 2012;28(11):2199-210. doi: https://doi.org/10.1590/S0102311X2012001100019

5. Tomazoni, Andréia et al. Evaluation of the patient safety culture in neonatal intensive care. Texto Contexto Enferm. 2015;24(1):161-69. doi: https://doi. org/10.1590/0104-07072015000490014

6. Sorra J, Gray L, Streagle S, Famolaro T, Yount N, Behm J. Hospital Survey on Patient Safety Culture: sser's guide. Rockville, MD: AHRQ; 2018 [cited 2019 Apr 20]. Available from: https://www.ahrq.gov/sites/default/files/wysiwyg/ professionals/quality-patient-safety/patientsafetyculture/hospital/userguide/ hospcult.pdf

7. Macedo TR, Rocha PK, Tomazoni A, Souza S, Anders JC, Davis K. The culture of patient safety from the perspective of the pediatric emergency nursing team. Rev Esc Enferm USP. 2016;50(5):756-62. doi: https://doi.org/10.1590/ s0080-623420160000600007

8. Andrade LEL, Lopes JM, Souza Filho MCM, Vieira Júnior RF, Farias LPC, Santos CCM, et al. Cultura de segurança do paciente em três hospitais brasileiros com diferentes tipos de gestão. Ciênc Saúde Coletiva. 2018;23(1):161-72. doi: https://doi.org/10.1590/1413-81232018231.24392015

9. Lessa SRO, Bezerra JMN, Barbosa SMC, Luz GOA, Borba AKOT. Prevalence and factors associated with the occurrence of adverse events in the hemodialysis service . Texto Contexto Enferm. 2018;27(3):e3830017. doi: https://doi. org/10.1590/0104-07072018003830017
10. Bezerra WR, Bezerra ALQ, Paranaguá TTB, Bernardes NJC, Teixeira CC. Occurrence of incidents at a surgical center: a documentary study. Rev Eletr Enf. 2015;17(4). https://doi.org/10.5216/ree.v17i4.33339

11. Ferreira PC, Dantas ALM, Diniz KD, Ribeiro KRB, Machado RC, Tourinho FSV. Adverse event versus medication error: perceptions of nursing staff acting in intensive care. J Res: Fundam Care Online. 2014 [cited 2019 Apr 20];6(2):72534. Available from: http://www.seer.unirio.br/index.php/cuidadofundamental/ article/view/3088/pdf_1272

12. Costa DB, Ramos D, Gabriel CS, Bernardes A. Patient safety culture: evaluation by nursing professionals. Texto Contexto Enferm. 2018;27(3):e2670016. doi: https://doi.org/10.1590/0104-070720180002670016

13. McHugh MD, Rochman MF, Sloane DM, Berg RA, Mancini ME, Nadkarni VM, et al. Better nurse staffing and nurse work environments associated with increased survival of in-hospital cardiac arrest patients. Med Care. 2016;54(1):74-80. doi: https://doi.org/10.1097/MLR.0000000000000456

14. Santiago THR, Turrini RNT. Organizational culture and climate for patient safety in Intensive Care Units. Rev Esc Enferm USP. 2015;49(spe):123-30. doi: https:// doi.org/10.1590/S0080-623420150000700018

15. Silva AT, Alves MG, Sanches RS, Terra FS, Resk ZMR. Nursing care and the focus on patient safety in the Brazilian scenario. Saúde Debate. 2016;40(111):292301. doi: https://doi.org/10.1590/0103-1104201611123

16. Novaretti MCZ, Santos EV, Quitério LM, Daud-Gallotti RM. Sobrecarga de trabalho da enfermagem e incidentes e eventos adversos em pacientes internados em UTI. Rev Bras Enferm. 2014;67(5):692-9. doi: https://doi.org/10.1590/00347167.2014670504

17. Braithwaite J, Herkes J, Ludlow K, Testa L, Lamprell G. Association between organisational and workplace cultures, and patient outcomes: systematic review. BMJ Open. 2017;7(11):e017708. doi: https://doi.org/10.1136/ bmjopen-2017-017708

18. Fujita S, Seto K, Ito S, Wu Y, Huang C, Hasegawa T. The characteristics of patient safety culture in Japan, Taiwan and the United States. BMC Health Serv Res. 2013;13:20. doi: https://doi.org/10.1186/1472-6963-13-20

19. Nascimento JSG, Rodrigues RR, Pires FC, Gomes BF. Passagem de plantão como ferramenta de gestão para segurança do paciente. Rev Enferm UFSM. 2018;8(3):544-59. doi: https://doi.org/10.5902/2179769229412

20. Birmingham P, Buffum MD, Blegen MA, Lyndon A. Handoffs and patient safety: grasping the story and painting a full picture. West J Nurs Res. 2014:37(11):1458-78. doi: https://doi.org/10.1177/0193945914539052

\section{- Corresponding author:}

Vitoria Sandri Pedroni

E-mail: vispedroni@gmail.com

\section{Associate editor: \\ Cecília Helena Glanzner}

Received: 05.20.2019

Approved: 09.16.2019

\section{Editor-in-chief:}

Maria da Graça Oliveira Crossetti 